\title{
Associated Factors of Long Acting Reversible Contraceptive Methods Utilization Among Women of Reproductive Age in Wolkite Town
}

\author{
Mohammed Derese Biru* Brihan Abera Kidus Yosef \\ Department of Statistics, College of Natural and Computational Science, Wolkite University
}

These authors contributed equally to this work

\begin{abstract}
Background: Unintended pregnancy and abortion are stubborn problems in many countries including Ethiopia. Long acting contraceptive methods prevent unintended pregnancy far better than using a short acting method. This research aimed to assess factors that affect long acting reversible contraceptive use among women of reproductive age group in Wolkite town, Southern Ethiopia.Methods: A cross sectional study was conducted in Wolkite town Guraghe zone southern Ethiopia. A total of 834 reproductive age group women's, were selected using systematic random sampling. Socio-economic, demographic and health related characteristics of the participants were collected using structured questionnaires and personal interview. Chi-square test of independency and Logistic regression model was employed to determine the associated factors of long acting reversible contraceptive use.Results: The proportion of long acting reversible contraceptive use in Wolkite town was $0.253(25.3 \%)$. Variables Statistically associated with long acting reversible contraceptive use were Age group of women between 30-34 $(\mathrm{OR}=2.387,95 \% \mathrm{CI}=1.011-5.635)$ and 35-39 $(\mathrm{OR}=4.62395 \% \mathrm{CI}=1.512-14.138)$, Source of information about LAC methods from sex of partner and from other $(\mathrm{OR}=2.028,95 \%, \mathrm{CI}=1.373-2.996$ and $\mathrm{OR}=0.457,95 \%$, $\mathrm{CI}=0.266-0.786)$ respectively, Awareness on IUD and DEPO methods $(\mathrm{OR}=0.562,95 \% \mathrm{CI}=0.363-0.872$ and $\mathrm{OR}=0.446,95 \% \mathrm{CI}=0.313=0.635)$ respectively, awareness on duration of implant usage from $3-5$ years $(\mathrm{OR}=0.238,95 \% \mathrm{CI}=0.117-0.481)$, Perception on the removal of LAC methods for possible response $(\mathrm{OR}=4.483$, 95\% CI=2.041-9.839)Conclusions: This study found that proportion of long acting reversible contraceptive use was $0.253(25.3 \%)$.
\end{abstract}

Keywords: Long Acting, Reversible Contraceptive and Women

DOI: $10.7176 / \mathrm{JHMN} / 85-03$

Publication date: January $31^{\text {st }} 2021$

\section{Background}

Many countries have policed to lower population growth and reduce fertility rate. Countries are working to be effective in utilization of modern family planning starting from awareness creating and educating their citizens.

Even though the decisions to use the family planning methods is depend on family interest it is cooperation work with different donators and nonprofit able organization. Long acting contraceptives methods have low failure rate, safer and cost effective than short acting contraceptive methods. There are two types of Long-acting contraceptive methods this include reversible contraceptive implants and intrauterine devices/ intrauterine contraceptive devices, plus the permanent methods of vasectomy and female sterilization. Long acting contraceptive method can avert pregnancy more than a year in one action without requirement of repeated procedures (1-4).

People have different choose to use birth control methods to have children when the time is right. Which was approved at the International Conference on Population and Development in 1994 (5). Family planning programmes have a lot of merits in decreasing fertility and maternal mortality rate. For this reason, modern contraceptive family planning methods have invaluable significance in order to succeed great levels women's sexual and reproductive health desires and it is crucial to deliver safe, effective and affordable modern contraceptive methods (6). Yet, insignificant number of women in Africa are using this modern contraceptive methods. Among this women's, higher proportion of them are user of non-long acting contraceptive methods, such as oral contraceptives and injectable. Some importance of using of contraception methods are to prevent unplanned pregnancies and illegal abortions in low-income countries like sub-Saharan Africa countries and this have a direct contribution to increase maternal and child health consequences. It also has possible to diminish poverty in this country by refining educational and economic outcomes for women $(7,8)$.

In sub-Saharan Africa, about $25 \%$ of women's and couples are not using any type of modern contraceptive methods including long acting contraceptive methods. According to some study conducted using data from four sub-Saharan African countries using demographic and health surveys show that the proportion of women currently using LACs is significantly lower than the proportion using short-acting methods. Similarly, not greater than 5\% of women who are using long acting contraceptive methods. For this matter, maternal fertility rates have not reduced considerably over the last three decades and have had negative consequences on women's sexual and 
reproductive health. In developing countries, 214 million women have unachievable contraceptive methods need, with utmost proportion was recorded of women who were living in Sub-Saharan Africa (21\%). If this unachieved situation was improved in Sub-Saharan Africa countries it is possible to prevent 67 million, 23 million unplanned pregnancies and births respectively as well as around 36 million abortions, and 76,000 maternal deaths each year (9-10).

As findings shows that, now days in Ethiopia the contraceptive prevalence rate (CPR) is $36 \%$, of which $35 \%$ using modern methods and $1 \%$ using none of modern methods, Likewise, the contraceptive termination rate (Percentage of contraceptive use periods out-of-date within 12 months) also shows that for all women age 15-49 who started periods of contraceptive use in the 5 years preceding the survey, $35 \%$ of the periods were stopped within 12 months. Reason for terminating a method is the desire to become pregnant $(42 \%)$, methods related to health concerns or side effects $(18 \%)$, wanting a more effective method $(11 \%)$, rare sex or husband away $(8 \%)$, and troublesomeness of use $(6 \%)(11)$. The study also reported that the utilization for all types and long term methods of contraceptive was $35.3 \%$, and $10.3 \%$ respectively. Injectable is the most commonly used modern method which used by $31 \%$ of currently married women. Conversely, only $5 \%$ and $3 \%$ of currently married women use implants and pills respectively. This has a consequence of high rates of unwanted pregnancies, unintentional deliveries and dangerous abortions leads to high maternal mortalities in the country (11-12).

There was no such a study that assessed the determinants of long acting reversible contraceptive at the study area. Therefore, this study aimed to identify to determinants of LARCs methods utilization among reproductive age women in Wolkite town. The finding of the study is an input for policy makers to make intervention that help in reduction of maternal mortality and morbidity through speeding up utilization of LACs method.

\section{Methods \\ Study Design}

This is a cross sectional study which targeted women of reproductive age in Wolkite town.

\section{Study Area Description}

This study was conducted in Wolkite town. According to the National population and housing census carried out in 2007, the population of the town was 33,406. Wolkite town is located in South Nations and Nationalities People Regional State, in Guraghe Zone, at a distance of $155 \mathrm{~km}$ from Addis Ababa.

\section{Sample size determination}

A sample size of 836 was determined using single population proportion with the assumption that the proportion of long acting contraceptive utilization of $8.62 \%$ (18) margin of error $2 \%$, Type I error of $5 \%$, and expected nonresponse rate of $10 \%$.

\section{Sampling and conduct of a survey}

Multi-stage sampling technique was utilized. Wolkite Town has a total of six kebeles/sub-districts. First kebeles were selected using simple random sampling method and selecting the households by systematic random sampling.

\section{Data collection instruments and process}

The study objective was achieved using quantitative data. A structured questionnaire was designed in local language (Amharic). Pre-testing was carried out on the target population for the purpose of validating the reliability of the instrument and familiarizing data collectors with the interview process.

\section{Data Analysis}

Data were entered into EPI-DATA 3.1 and exported to SPSS version 23 for analysis. Descriptive statistics, chisquare test of association and binary logistic regression analysis was used. In the binary logistic regression analysis ever use of long acting reversible contraceptive was used as the dependent variable. Statistical significance level was determined as $\mathrm{p}<0.05$.

\section{Results}

\section{Socio-Economic, Demographic and Health Related Characteristics}

The proportion of women who used long acting reversible contraceptive methods in Wolkite town, southern Ethiopia was 0.253(25.3\%).

The highest percent of respondents who used LAC was recorded in the age group 25-29 (35.5\%). The age groups 18-24, 30-34 and 35-39 followed with percentages of $23.2 \%, 18.0 \%$ and $13.3 \%$, respectively.

Among the five categories of ethnic group, Guraghe and Amhara had the first and second highest women who used LAC with $43.6 \%$ and $17.5 \%$, respectively. The proportion of women who used long acting reversible contraception decreased from $38.9 \%$ for government employed women to $29.9 \%$ for housewives. Students, 
merchants and daily laborer had proportions $9.5 \%, 13.7 \%$ and $8.1 \%$, respectively. From a total of $211,37.4 \%$ of the Orthodox religious follower women used long acting contraception 30.3\%, 19.9\% and 9.0\%, Muslims, protestant and Catholics religious follower women were respectively used long acting contraception.

Majority of the women (93.8\%) had sexual partner "during the study" and use long acting reversible contraceptive method. Whereas only $6.2 \%$ of the women who didn't have sexual partner and used long acting contraception method.

Regarding awareness on duration of implant usage for 3-5 years (86.3\%) was recorded among women who used long acting reversible contraception method then followed by awareness on duration of implant usage for 3 month and 10 years $(4.3 \%, 2.8 \%)$ respectively. Likewise, regarding the health service delivery for long acting reversible contraceptive method $51.2 \%$ responded that the health service was good, followed by women who responded that it was very good health service (39.8\%). Only $1.9 \%$ of the participants responded that the health service was very poor.

Lastly regarding payment for LARC method most women responded that the payment "is free" $(50.7 \%)$ which is followed by "payment is fair" $(28.9 \%)$.

The chi-square test of association result shows that the independent variables Ethnic Group, Woman's religion, Employment status, Woman's age, Have sex partner, Implant Effectiveness, Health Service, Trust Health Service and Payment of LAC were significantly associated with the dependent variable of using long acting reversible contraceptive methods(Table 1)

The respondents heard about the methods from different sources of information.

Based on figure 1 best describes of all the eligible women in the study, $81.7 \%, 78.6 \%$ and $78.5 \%$ heard about long acting reversible contraception from radio, health personnel and TV, respectively. Least percent of them $(1.8 \%)$ heard about LAC from other sources such as social Medias, gender clubs and offices. $12.3 \%, 16.9 \%$ and $19.8 \%$ heard from magazines, posters and their sex partners, respectively.

\section{Logistic Regression Analysis}

In this study binary logistic regression was employed to identify the associated explanatory variables with the dependent variable of using long acting reversible contraceptive methods. Accordingly, Age of women, Source of information about LAC methods from sex partner or not and from other source, Awareness on IUD and DEPO are LAC methods, Awareness about on duration of implant usage, Perception on the removal of LAC methods were included in the model. The output of the binary logistic analysis is shown in the table 2 .

From table 2 the odds of using LAC for age groups 30-34 and 35-39 were 2.387 and 4.623 times more likely when compared with women in the age group 45-49 controlling for the other variable in the model.

The odds of using long acting reversible contraception methods were 2.028 more likely for women who heard about LAC from sex partner than not heard from sex partner controlling for the other variables in the model.

The odds of using long acting reversible contraceptive methods were 54.3\% less likely for women who responded "heard about LAC from no any other sources" than responded "heard about LAC from other sources" controlling for the other variables in the model.

The odds of using long acting reversible contraceptive methods were $43.8 \%$ less likely for women who said IUD is a LAC method than who did not said IUD is a LAC method controlling for the other variables in the model.

The odds of using long acting reversible contraception methods were $55.4 \%$ less likely for women who answered as injectable (Depo-Provera) is a LAC method when compared with who did not answered injectable (Depo-Provera) is a LAC method controlling for the other variables in the model.

The odds of using long acting reversible contraceptive methods were $76.2 \%$ less likely for women who have awareness on duration of implant usage for 3-5 years when we compared with women who have awareness about duration of implant usage for 10 years controlling for the other variables in the model.

The odds of using long acting reversible contraception methods were 4.483 more likely for women who response on the perception of removal of long acting contraceptive is possible when compared with those who did not have any response controlling the effect of the other variables in the model constant.

\section{Discussion}

This cross-sectional study attempts to assess the determinant factors affecting usage of LAC among women of reproductive age and showed that the overall usage of LACs was $25.3 \%$. The study result was higher than the study done in Nekemte town (20\%), Arba Minch (13.1\%). This may be due to increased awareness of communities about long acting and contraceptive methods and promotion about long acting contraceptive methods by governmental organization found in the town however our finding was lower while we compared with study conducted in Adaba town (30.3\%) and Adigrat town (37\%). This decrement might be happened due to socioeconomic and women life standard status difference in towns (13-16).

In this study the highest percentage of awareness of women in reproductive age group regarding to duration of implant usage was responded that it used for $3-5$ years $(86.3 \%)$ was recorded. The result is in line with study 
done in Adaba town, West Arsi Zone, Oromia, Ethiopia (15).

The study shows that regarding to women's age group highest percent of respondents who used LAC was recorded in the age group 25-29 (35.5\%) and followed by age groups 18-24 (23.2\%). This result is almost related with the study conducted in Mekelle and in Dabat Health and Demographic Surveillance System site, northwest Ethiopia. This fact might be related to women in this age group not need to have more number of children (17-18).

This study reveals that presence of Radio/TV had important contribution in encouraging current usage of LACs. Of all the eligible women in the study, $81.7 \%, 78.6 \%$ and $78.5 \%$ heard about long acting reversible contraception from the radio, health personnel and TV. This might be due to having exposure to media can increase knowledge and awareness of women on usage of long acting reversible contraception (13 \& 19).

Similarly, employment status of women was found to be statistically associated with long acting reversible contraceptive method use. As well as from chi-square test of association result shows that the factors like Ethnic Group, Woman's religion, Have sex partner, Implant Effectiveness, Health Service, Trust Health Service and Payment of LAC were significantly associated with dependent variable of using long acting reversible contraceptive methods in the Wolkite town $(14,17)$.

Regarding awareness of women on IUD and DEPO are LAC methods were found to be statistically associated with long acting reversible contraceptive method use. Accordingly, women who responded IUD and DEPO are LAC methods were negatively associated with use of long acting contraceptives methods $((\mathrm{OR}=0.562,95 \%$ $\mathrm{CI}=0.363-0.872$ and $\mathrm{OR}=0.446,95 \% \mathrm{CI}=0.313=0.635)$ respectively than women who did not answered $\mathrm{DEPO}$ and IUD are LAC method(20-22).

Our finding showed that on awareness about duration of implant usage had a significant association with the study variable. Thus women who have awareness about on duration of implant usage is 3-5 years were negatively associated with use of long acting contraceptives methods $(\mathrm{OR}=0.238,95 \% \mathrm{CI}=0.117-0.481)$ when we compared with women who were have awareness about on duration of implant usage is 10 years (20-22).

This study examined socio-economic, demographic and health service related factors that affect the use of long acting reversible contraceptive methods (IUD and implant) in Wolkite town among women in the reproductive age.

The result showed that even if majority of the women population heard about the contraceptive methods only few were actually using them. The descriptive statistics result showed that, $25.30 \%$ women in reproductive age where used long acting reversible contraceptive methods in Wolkite town Southern of Ethiopia.

On the other hand, the Chi-square test of independency and binary logistic regression confirmed that, at $95 \%$ confidence level, Ethnic Group, Woman's religion, Employment status, Woman's age, Have sex partner, Health Service, Trust Health Service, Payment of LAC, Source of information about LAC methods, Awareness of LAC methods, Awareness about on duration of implant usage, Perception on the removal of LAC methods were found significantly associated variables with response variable of using long acting reversible contraceptive methods

\section{List of Abbreviations}

LAC: long acting contraceptive; ICPD: International Conference on Population Development; IUCD: Intra Uterine Contraceptive Devices; IUD: Intra Uterine Device;

\section{Ethics approval and consent to participate}

Ethical clearance for the proposed study was obtained from the ethical review committee of Wolkite University. Communication with the Town and different kebele administrators was made through formal letter obtained from Wolkite University. The respondents were explained in detail about the research.

The purpose and importance of the study was explained to the participants. Data were collected after full informed written consent was obtained. The respondents were treated with respects and their rights to privacy and confidentiality were observed through anonymity.

\section{Consent for publication}

Not applicable.

\section{Availability of data and material}

The datasets used and analyzed during the study available from the corresponding author on reasonable request.

\section{Competing Interests}

The authors declare that they have no competing interests.

\section{Source of fund}

This study was financially supported only for data collection by Wolkite University, Ethiopia. 


\section{Authors' Contributions}

BA wrote the proposal, participated in data collection, analyzed the data and drafted the paper. KY and MD approved the proposal with some revisions, participated in data collection, entry and revised subsequent drafts of the paper. All authors read and approved the final manuscript.

\section{Acknowledgements}

First, we would like to thank all women who participated in this study. We also want to thank Wolkite University for the financial support and for all the assistance in the process of conducting the research.

\section{Author Details}

1,2,3 Department of Statistics, College of Natural and Computational Science, Wolkite University, Wolkite, Ethiopia.

\section{Reference}

1. Sundrama A, Vlassoff M, Bankole A, Gebrehiwote Y. Benefits of Meeting the Contraceptive Needs of Ethiopian Women: In Brief, New York. Guttachmar institute July, 2010.

2. US Agency for International Development (USAID). Using Quantification to Support Introduction and Expansion of Long-Acting and Permanent Methods of Contraception. USA: USAID|Deliver Project, Engender Health/The RESPOND Project October, 2010.

3. Family Health International (FHI), Long-Acting and Permanent Methods: Highlights of the Contraceptive and Reproductive Health Technologies Research and Utilization Program, 2005-2010. 2010

4. Teferra AS, Wondifraw AA. Determinants of long acting contraceptive use among reproductive age women in Ethiopia: Evidence from EDHS 2011. Sci J Public Heal. 2015;3(1):143-9.

5. United Nations Population Fund. Part One, Section VII: Reproductive Rights and Reproductive Health, B. Family planning: Actions. UN; New York: 1994. Programme of Action of the International Conference on Population \& Development (ICPD).

6. Prata N, Fraser A, Huchko MJ, Gipson JD, Withers M, Lewis S, Ciaraldi EJ, Upadhyay UD. ebbbbWomens empowerment and family planninig: a review of the literature. J Biosoc Sci. 2017;49(6):713-43.

7. US Agency for International Development (USAID). Long Acting and Permanent Methods of Contraception: Meeting Clients' Needs: Issue Brief. August 2006.

8. Ewerling F, Victora CG, Raj A, Coll CVN, Hellwig F, Barros AJD. Demand for family planning satisfied with modern methods among sexually active women in low- and middle-income countries: who is lagging behind? Reprod Health. 2018;15(12):1-10.

9. Guttmacher Institute. Adding it up: investing in contraception and maternal and new born health, 2017. https://www.guttmacher.org/fact-sheet/adding-it-up-contraception-mnh-2017.

10. Medhanyie AA, Desta A, Alemayehu M, Gebrehiwot T, Abraha TA. Factors associated with contraceptive use in Tigray, North Ethiopia. Reprod Health. 2017;14(27):1-11.

11. Central Statistical Agency (Ethiopia) and ICF International. Ethiopia demographic and health survey 2016. Addis Ababa: Central Statistical Agency (Ethiopia); 2016.

12. Ayele W, Tesfaye H, Gebreyes R, Gebreselassie aT. Trends and determinants of unmet need for family planning and Programme options, Ethiopia. Further analysis of the 2000, 2005 and 2011 demographic and health surveys. DHS further analysis reports. Reports no. 81. Calverton: ICF International; 2013.

13. Melka AS, Tekelab T, Wirtu D. Determinants of long acting and permanent contraceptive methods utilization among married women of reproductive age groups in western Ethiopia: a cross-sectional study. Pan Afr Med J. 2015;

14. Shegaw G, Mohammed AA, Nadew K, Tamrat K, Zeru G, Desta H YW. Long Acting Contraceptive Method Utilization and Associated Factors among Reproductive Age Women in Arba Minch Town, Ethiopia. Greener J Epidemiol Public Heal. 2014;2(1):023-31.

15. Fekadu H, Kumera A, Yesuf EA, Hussien G, Tafa M. Prevalence and Determinant Factors of Long Acting Contraceptive Utilization among Married Women of Reproductive Age in Adaba Town, West Arsi Zone, Oromia, Ethiopia. J Women's Health Care. 2017: 6:360. doi:10.4172/2167-0420.1000360

16. Gebreyesus B, Berhe S, Bayray A. Assessment of long acting and permanent contraceptive method utilization and associated factors among married women of reproductive age group in Adigrat town, Tigray region, Ethiopia. 2015; 2: 36-45

17. Alemayehu M, Belachew T, Tilahun T. Factors associated with utilization of long acting and permanent contraceptive methods among married women of reproductive age in Mekelle town, Tigray region, North Ethiopia. 2012; 12: 6.

18. Alemayehu GA, Fekadu A, Yitayal M, Kebede Y, Abebe SM, Ayele TA, et al. Prevalence and determinants of contraceptive utilization among married women at Dabat Health and Demographic Surveillance System site , northwest Ethiopia. BMC Women’s Heal. 2018;1-7. 
19. Central Statistical Agency Ethiopia and ORC Macro Ethiopia Demographic and Health Survey (EDHS) 2011. Addis Ababa, Ethiopia and Calverton, Maryland. USA: Central Statistical Agency and ORC Macro. 2012; 93-99. PubMed | Google Scholar

20. Babalola S, Fatusi A: Determinants of use of maternal health services inNigeria - Looking beyond individual and household factors. BMCPregnancy and Childbirth. 2009, 9(43)

21. Beekle AT, McCabe C: Awareness and determinants of family planning practice in Jimma, Ethiopia. Int Nurs Rev 2006, 53(4):269-76.

22. Fantahun M: Comparative study of the characteristics of family planning service users and non-users in northwest Ethiopia. Afr J Reprod Health 2006, 10(1):62-70

Table 1. Socio-Economic, Demographic and Health Related Characteristics of Respondents by dependent variable with their test of association

\begin{tabular}{|c|c|c|c|c|c|}
\hline \multirow{2}{*}{\multicolumn{2}{|c|}{ Variables }} & \multicolumn{2}{|c|}{ Ever used IUD or implant } & \multicolumn{2}{|c|}{ Chi-square } \\
\hline & & Yes N(\%) & No N(\%) & DF & p-value \\
\hline \multirow[t]{6}{*}{ Ethnic Group } & Guraghe & $92(43.6 \%)$ & $268(43.0 \%)$ & 5 & 0.015 \\
\hline & Silte & $15(7.1 \%)$ & $27(4.3 \%)$ & & \\
\hline & Amhara & $37(17.5 \%)$ & $136(21.8 \%)$ & & \\
\hline & Wolayta & $18(8.5 \%)$ & $21(3.4 \%)$ & & \\
\hline & Oromo & $28(13.3 \%)$ & $91(14.6 \%)$ & & \\
\hline & Others & $21(10.0 \%)$ & $80(12.8 \%)$ & & \\
\hline \multirow[t]{5}{*}{ Woman's religion } & Protestant & $42(19.9 \%)$ & $112(18.0 \%)$ & 4 & 0.007 \\
\hline & Orthodox & $79(37.4 \%)$ & $285(45.7 \%)$ & & \\
\hline & Catholic & $19(9.0 \%)$ & $35(5.6 \%)$ & & \\
\hline & Muslim & $64(30.3 \%)$ & $187(30.0 \%)$ & & \\
\hline & Others & $7(3.3 \%)$ & $4(0.6 \%)$ & & \\
\hline \multirow[t]{6}{*}{ Employment status } & Student & $20(9.5 \%)$ & $51(8.2 \%)$ & 5 & 0.00 \\
\hline & House Wife & $63(29.9 \%)$ & $174(27.9 \%)$ & & \\
\hline & Merchant & $29(13.7 \%)$ & $136(21.8 \%)$ & & \\
\hline & Daily laborer & $17(8.1 \%)$ & $26(4.2 \%)$ & & \\
\hline & G. employee & $82(38.9 \%)$ & $205(32.9 \%)$ & & \\
\hline & Others & $0(0.0 \%)$ & $31(5.0 \%)$ & & \\
\hline \multirow[t]{6}{*}{ Woman's age } & $18-24$ & $49(23.2 \%$ & $118(18.9 \%)$ & 5 & 0.023 \\
\hline & $25-29$ & $75(35.5 \%)$ & $200(32.1 \%)$ & & \\
\hline & $30-34$ & $38(18.0 \%)$ & $118(18.9 \%)$ & & \\
\hline & $35-39$ & $28(13.3 \%)$ & $103(16.5 \%)$ & & \\
\hline & $40-44$ & $11(5.2 \%)$ & $64(10.3 \%)$ & & \\
\hline & $45-49$ & $10(4.7 \%)$ & $20(3.2 \%)$ & & \\
\hline \multirow[t]{2}{*}{ Have sex partner } & No & $13(6.2 \%)$ & $119(19.1 \%)$ & 1 & 0.00 \\
\hline & Yes & $198(93.8 \%)$ & $504(80.9 \%)$ & & \\
\hline \multirow[t]{5}{*}{ Awareness on Implant usage } & For 3 months & $9(4.3 \%)$ & $20(3.2 \%)$ & 4 & 0.00 \\
\hline & For a month & $2(0.9 \%)$ & $80(1.3 \%)$ & & \\
\hline & For 3-5 years & $182(86.3 \%)$ & $402(64.5 \%)$ & & \\
\hline & For 10 years & $6(2.8 \%)$ & $91(14.6 \%)$ & & \\
\hline & Other & $0(0.0 \%)$ & $4(0.6 \%)$ & & \\
\hline \multirow[t]{5}{*}{ Health Service } & Excellent & $9(4.3 \%)$ & $9(1.4 \%)$ & 4 & 0.00 \\
\hline & Very good & $84(39.8 \%)$ & $158(25.4 \%)$ & & \\
\hline & Good & $108(51.2 \%)$ & $391(62.8 \%)$ & & \\
\hline & Poor & $6(2.8 \%)$ & $40(6.4 \%)$ & & \\
\hline & Very poor & $4(1.9 \%)$ & $11(1.8 \%)$ & & \\
\hline \multirow[t]{4}{*}{ Trust Health Service } & High & $61(28.9 \%)$ & $154(24.7 \%)$ & 4 & 0.00 \\
\hline & Medium & $109(51.7 \%)$ & $244(39.2 \%)$ & & \\
\hline & Low & $22(10.4 \%)$ & $148(23.8 \%)$ & & \\
\hline & Very low & $9(4.3 \%)$ & $19(3.0 \%)$ & & \\
\hline \multirow[t]{4}{*}{ Payment of LAC } & It is expensive & $12(5.7 \%)$ & $58(9.3 \%)$ & 3 & 0.00 \\
\hline & It is fair & $61(28.9 \%)$ & $338(54.3 \%)$ & & \\
\hline & It is cheap & $31(14.7 \%)$ & $114(18.3 \%)$ & & \\
\hline & It is free & $107(50.7 \%)$ & $87(14.0 \%)$ & & \\
\hline Total & & $211(25.3 \%)$ & $623(74.7 \%)$ & & \\
\hline
\end{tabular}


Table 2: -Result of Logistic Regression Model

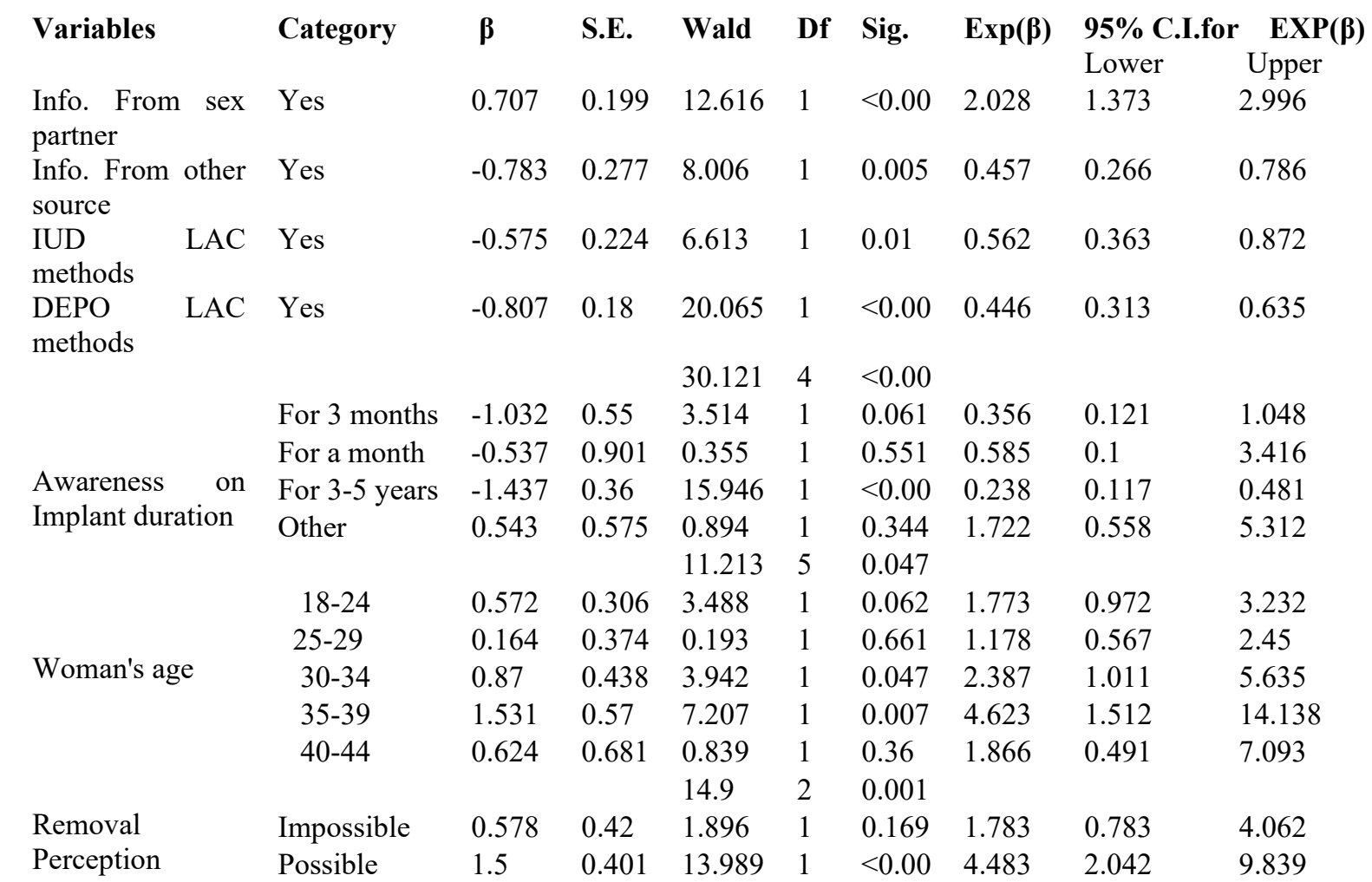

$\beta=$ coefficient value; S.E. $=$ Standard Error $; D f=$ Degree of Freedom; $\operatorname{Exp}(\beta)=$ Odds Ratio; C.I $=$ Confidence Interval

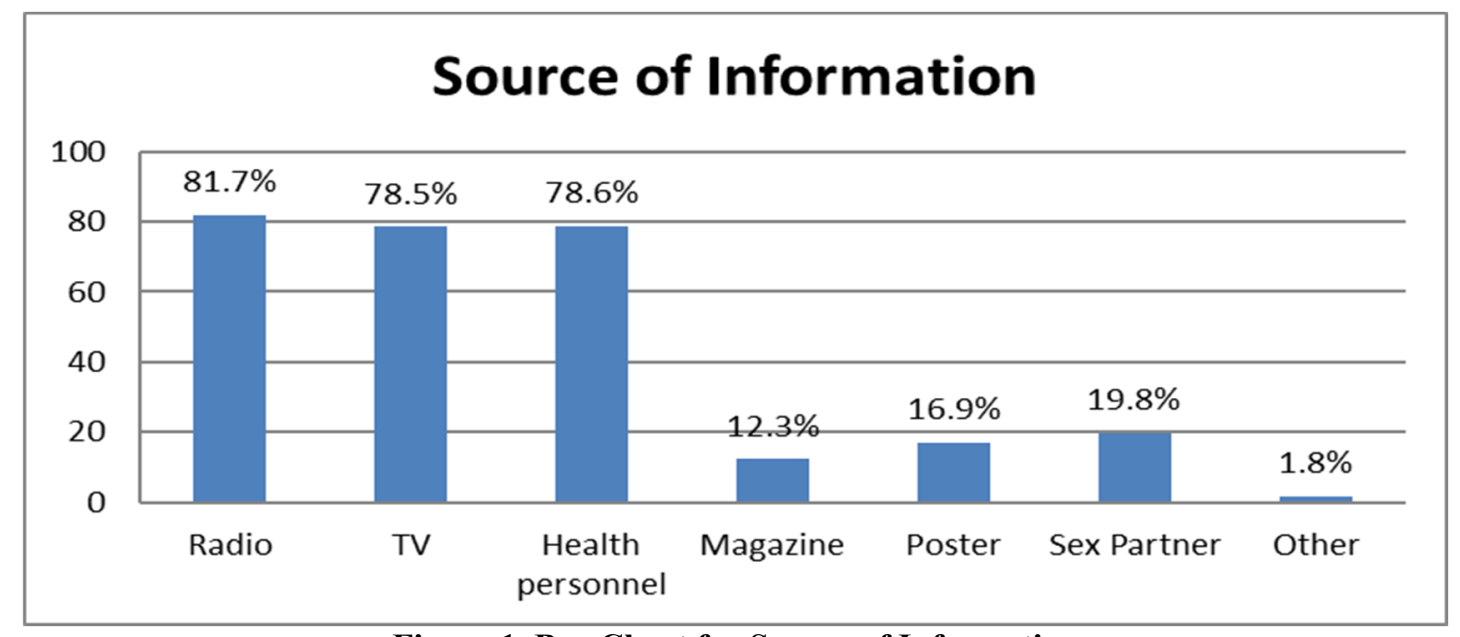

Figure 1. Bar Chart for Source of Information 